\title{
Micropropagação do abacaxizeiro ornamental
}

\author{
Moacir Pasqual'; Flávia C Santos²; Milene A de Figueiredo³; Keize P Junqueira ${ }^{4}$; Juliana C de Rezende ${ }^{2}$; \\ Ester A Ferreira ${ }^{5}$ \\ ${ }^{1}$ UFLA-DAG, C. postal 37; 37200-000 Lavras-MG; ${ }^{2}$ Doutoranda Agronomia/Fitotecnia, UFLA; ${ }^{3}$ Doutoranda Agronomia/Fisiologia, \\ UFLA; ${ }^{4}$ Doutoranda Inst. Ciências Biológicas; Fitopatologia, UnB; ${ }^{5}$ Pos-doutoranda, UFLA; ${ }^{2,4}$ Bolsista CNPq; ${ }^{3}$ Bolsista CAPES; \\ ${ }^{5}$ Bolsista FAPEMIG; mpasqual@ufla.br
}

\section{RESUMO}

O Ananas comosus var. erectifolius, cultivar de abacaxi ornamental, tem apresentado grande interesse para paisagistas e floricultores do Brasil e do exterior, por ser uma planta ornamental tropical, exótica e rústica. A produção de plantas ornamentais a partir de técnicas de cultura de tecidos apresenta-se como uma alternativa viável para a obtenção de um grande número de plantas com qualidade genética e fitossanitária, em um curto espaço de tempo, suprindo, assim, a necessidade do mercado na aquisição de mudas com qualidade comprovada. Estudou-se a influência das concentrações de BAP (0; 0,$5 ; 1,0$ e $\left.1,5 \mathrm{mg} \mathrm{L}^{-1}\right)$ e ANA $\left(0,0 ; 0,12 ; 0,24 ; 0,48 \mathrm{mg} \mathrm{L}^{-1}\right)$ no meio de cultura MS com 0; 2,5; 5,0; e 7,5 g L ${ }^{-1}$ de ágar, visando estabelecer um protocolo para multiplicação e enraizamento in vitro de brotos de abacaxizeiro ornamental. Brotações com 1,5 \pm 0,5 cm, já estabelecidas in vitro, oriundas das gemas da coroa do fruto do abacaxizeiro ornamental, foram inoculados assepticamente nos frascos. Após inoculados, os explantes foram mantidos em sala de crescimento com luminosidade em torno de 35 ìmol m $\mathrm{m}^{-2} \mathrm{~s}^{-1}, 26 \pm 1^{\circ} \mathrm{C} \mathrm{e}$ fotoperíodo de 16 horas. Após 45 dias observou-se que a multiplicação in vitro do abacaxi ornamental é viável em meio MS líquido acrescido de BAP $1,5 \mathrm{mg} \mathrm{L}^{-1}$ e o enraizamento também em meio MS líquido, na ausência de reguladores de crescimento.

Palavras-chave: Ananas comosus var. erectifolius, bromeliceae, cultura de tecidos, enraizamento, multiplicação.

\begin{abstract}
Protocol for in vitro micropropagation of ornamental pineapple

The Ananas comosus var. erectifolius is an ornamental pineapple cultivar which greatly interests Brazilians and foreign landscapers and flower producers for being an exotic and rustic tropical ornamental plant. The market demand for high quality of cuttings requires efficient methods of propagation and in this context the tissue culture stands out as a viable alternative to obtain plants with genetic and phytossanitary quality in a short time. In the present work we studied the influence of concentrations of BAP $(0 ; 0.5 ; 1.0$; $\left.1.5 \mathrm{mg} \mathrm{L}^{-1}\right)$ and NAA $\left(0 ; 0.12 ; 0.24 ; 0.48 \mathrm{mg} \mathrm{L}^{-1}\right)$ in the MS medium culture within $0 ; 2.5 ; 5.0 ; 7.5 \mathrm{~g} \mathrm{~L}^{-1}$ of agar, in order to establish an in vitro protocol for multiplication and rooting of ornamental pineapple. Plantlets with $1.5 \pm 0.5 \mathrm{~cm}$ already established in vitro, extracted from buds of ornamental pineapple fruits crown were inoculated aseptically in flasks. After inoculation the plantlets were kept in a growth room at $26 \pm 1^{\circ} \mathrm{C}, 35 \mathrm{imol} \mathrm{m} \mathrm{m}^{-2} \mathrm{~s}^{-1}$ irradiance and a 16-hour photoperiod. After 45 days we observed that the multiplication of ornamental pineapple is viable at liquid MS medium with BAP $1.5 \mathrm{mg} \mathrm{L}^{-1}$ and the rooting is also increased in liquid MS medium in absence of growth regulators.
\end{abstract}

Keywords: Ananas comosus var. erectifolius, Bromeliacea, tissue culture, rooting, multiplication.

\section{(Recebido para publicação em 20 de julho de 2007; aceito em 13 de fevereiro de 2008)}

$\mathrm{O}$ s sistemas de produção de plantas ornamentais evoluíram muito por constituírem uma atividade extremamente competitiva, exigente em tecnologias, conhecimentos avançados e comercialização eficiente.

A produção de plantas ornamentais a partir de técnicas de cultura de tecidos pode ser uma alternativa viável na obtenção de grande número de plantas com qualidade genética e fitossanitária em curto espaço de tempo, suprindo assim a necessidade dos produtores de flores e plantas ornamentais na aquisição de mudas com qualidade comprovada.

O Ananas comosus var. erectifolius, cultivar de abacaxi ornamental, tem apresentado grande interesse para paisagistas e floricultores do Brasil e do exterior, por ser uma planta ornamental tropical, exótica e rústica. Atualmente, o Brasil é o único país que possui plantios comerciais de $A$. comosus var. erectifolius (Borges et al., 2003). O abacaxizeiro ornamental caracteriza-se por ser terrestre, desenvolvendo-se geralmente em campo aberto sob alta luminosidade, em ambientes de solos arenosos e de clima tropical. Apresenta folhagens rígidas, eretas, sem espinhos e de coloração púrpura. As folhas crescem até $1,0 \mathrm{~m}$ de comprimento com largura de aproximadamente $3,5 \mathrm{~cm}$, em margens lisas e ápice de ponta aguda (Smith \& Dows, 1979), porém, mais finas quando comparadas com a folhagem do abacaxi comestível. Apresenta inflorescência globosa, sustenta brácteas com flores completas e pequenas (Leal \& Amaya, 1991). Sua infrutescência mede de 8 a $10 \mathrm{~cm}$, disposta na posição apical da haste que pode medir até 80 cm (Correia et al., 1999).

O processo de cultura de tecidos vegetais compreende um conjunto de técnicas nas quais um explante (célula, tecido ou órgão) é isolado sob condições assépticas, em meio nutritivo artificial. Este processo baseia-se no princípio da totipotencialidade das células, ou seja, qualquer célula de organismo vegetal apresenta todas as informações genéticas necessárias à regeneração de uma planta completa (Pasqual et al., 2001; Gallo \& Crocomo, 1995).

A propagação de espécies vegetais in vitro apresenta vantagens em relação aos métodos convencionais, como a multiplicação de clones em qualquer época do ano, produção de espécies que dificilmente seriam propagadas por 
métodos convencionais, rápida multiplicação clonal de espécies raras, além da eliminação de vírus (Gallo \& Crocomo, 1995). Dependendo da finalidade da propagação, conforme descrito por Murashige (1974), a cultura de tecidos de plantas pode ser feita utilizando como propágulo inicial tecidos meristemáticos (gemas axilares, regiões apicais e o meristema propriamente dito) e/ou explantes não meristemáticos (pecíolo, pedúnculos e o limbo foliar).

Os meios utilizados para cultura de células, tecidos e órgãos de plantas fornecem as substâncias essenciais para o crescimento dos tecidos e controlam, em grande parte, o padrão de desenvolvimento in vitro (Caldas et al., 1998).

As citocininas são utilizadas em cultura de tecidos para estimular a divisão celular e atuam, conseqüentemente, no processo de morfogênese (George, 1996). Das citocininas comercialmente disponíveis, o BAP (6benzilaminopurina) é a que geralmente proporciona melhores resultados (Grattapaglia \& Machado, 1998). O BAP é uma citocinina sintética muito utilizada devido à sua efetividade e baixo custo em relação às outras (Krikorian, 1991). Este regulador de crescimento induz à formação de grande número de brotos e leva a alta taxa de multiplicação em muitos sistemas de micropropagação (Hu \& Wang, 1983), cuja concentração pode variar bastante em função da espécie e do tipo do explante.

Várias auxinas (ANA, AIA, AIB, 2,4-D, entre outras) têm proporcionado respostas diferentes in vitro (Caldas et al., 1998). As auxinas podem ser necessárias para complementar o teor endógeno ou suprir as necessidades de meristemas isolados. Pierik et al. (1984), examinando a influência da ação de auxinas na germinação de sementes e crescimento posterior de plântulas de três espécies de Bromeliaceae, constataram que o ANA, adicionado ao meio MS, foi a auxina mais eficiente para promover o crescimento de brotos e de raízes, sendo utilizada em concentrações entre 0,5 e $0,8 \mathrm{mg} \mathrm{L}^{-1}$.

$\mathrm{O}$ ágar é o agente comumente utilizado na solidificação dos meios de cultura (George, 1993; Singha, 1984). Existem diversas marcas comerciais de ágar, porém recomenda-se otimizá-lo no preparo do meio, visto que o ágar é considerado o componente de custo mais elevado do meio de cultura (Peixoto \& Pasqual, 1995; George, 1993; Singha, 1984). As concentrações mais elevadas de ágar dificultam o contato do explante com o meio, limitando a absorção de compostos, fato este observado por Oliveira (1994) em microestacas de crisântemo. Peixoto \& Pasqual (1995) e Singha (1982) verificaram ainda que o aumento da concentração de ágar não foi prejudicial tanto para a taxa de multiplicação das brotações, como para o crescimento; além disso, os valores das massas fresca e seca foram fortemente reduzidos. O mesmo foi constatado com o ganho relativo de massa fresca das culturas de ápices de brotações de kiwi (Monette, 1986). O objetivo do trabalho foi estabelecer um protocolo para multiplicação e enraizamento in vitro de brotos de abacaxizeiro ornamental.

\section{MATERIAL E MÉTODOS}

Brotos com $1,5 \pm 0,5 \mathrm{~cm}$ provenientes de gemas da coroa do fruto do abacaxizeiro ornamental foram inoculados em meio de cultura MS. O pH do meio foi ajustado para $5,8 \pm 1$. Após o preparo, $60 \mathrm{~mL}$ de meio de cultura foram distribuídos em frascos com capacidade de $250 \mathrm{~mL}$, os quais foram vedados com tampas de polipropileno, identificados e autoclavados a $121^{\circ} \mathrm{C}$ por 20 min. A inoculação foi feita em câmara de fluxo laminar horizontal. Após a inoculação, os frascos foram colocados em sala de crescimento com luminosidade em torno de 35 ìmol $\mathrm{m}^{-2}$ $\mathrm{s}^{-1}, 26 \pm 1^{\circ} \mathrm{C}$ e fotoperíodo de $16 \mathrm{~h}$, onde permaneceram por 45 dias.

Os tratamentos do primeiro experimento constituíram-se de quatro concentrações de BAP (0; 0,5; 1,0 e 1,5 mg $\left.\mathrm{L}^{-1}\right)$ combinadas com quatro de ágar ( 0 ; 2,5; 5,0; e 7,5 $\mathrm{g} \mathrm{L}^{-1}$ ), e no segundo experimento quatro concentrações de ANA (0; 0,$12 ; 0,24$ e $\left.0,48 \mathrm{mg} \mathrm{L}^{-1}\right)$ e quatro de ágar $(0 ; 2,5 ; 5,0$; e 7,5 g L'-1), perfazendo um fatorial 4 x 4 com quatro repetições e três frascos por parcela, em delineamento inteiramente casualizado.

No primeiro experimento foram avaliadas as características: altura e núme- ro de brotos, massas fresca e seca da plântula; no segundo experimento foram realizados: altura da parte aérea, número de raízes e comprimento do sistema radicular, massas fresca e seca da plântula.

\section{RESULTADOS E DISCUSSÃO}

Para a variável altura média dos brotos, os melhores resultados foram obtidos utilizando-se $2.5 \mathrm{~g} \mathrm{~L}^{-1}$ de ágar na ausência de BAP, registrando-se 9,60 $\mathrm{cm}$. Os tratamentos utilizando 0; $1.0 \mathrm{e}$ $1.5 \mathrm{mg} \mathrm{L}^{-1}$ de BAP respectivamente, apresentaram comportamento semelhante, ou seja, com o acréscimo das concentrações de BAP houve redução na altura média de brotos (Figura 1). Resultados semelhantes foram obtidos por outros autores, a exemplo de Paiva et al. (1997) que, trabalhando com gloxínia, observaram redução do tamanho de brotos com o aumento das concentrações de BAP. Moreira (2001), trabalhando com abacaxizeiro cv. Pérola, observou resultados semelhantes, sendo que o meio MS sem regulador de crescimento mostrou-se mais eficiente para se obter melhor desenvolvimento das plantas. Outros autores também têm observado efeitos negativos desse regulador de crescimento no alongamento de brotações em espécies como crisântemo e morangueiro (Pasqual et al., 1998; Oliveira, 1994).

O aumento das concentrações de BAP, na ausência de ágar, promoveu aumento linear no número de brotos e quando se utilizou $1,5 \mathrm{mg} \mathrm{L}^{-1}$ do regulador alcançou-se o número máximo de 21 brotações por explante (Figura 2). A concentração de $1,5 \mathrm{mg} \mathrm{L}^{-1}$ de BAP promoveu a melhor resposta para o número de brotações na micropropagação de Ananas comosus (L.) (Almeida et al., 2002). Segundo Zaerr \& Mapes (1985), o BAP é a citocinina mais potente para promover multiplicação de partes aéreas e indução de gemas adventícias e é também economicamente mais viável por apresentar menor custo. À medida que se aumentaram as concentrações de ágar, houve redução na formação de brotos, provavelmente devido a menor disponibilidade de nutrientes. Moreira (2001), estudando suplementação 
hormonal do meio MS no crescimento in vitro de mudas de abacaxizeiro cv. Pérola, verificou que o número máximo de brotações ocorreu na ausência de ágar. As concentrações 5,0 e 7,5 g L-1 de ágar não foram apresentadas na Figura 2 devido a não significância entre suas médias pelo teste de regressão. o BAP é uma das citocininas mais utilizadas na indução de brotos (Rocca \& Mroginki, 1991). Entretanto, a concentração recomendada varia consideravelmente entre laboratórios que trabalham com micropropagação de Ananas sp. Para a cultivar de abacaxizeiro Red Spanish, a maior proliferação de brotos ocorreu em meio MS líquido suplementado com 0,3 mg L $\mathrm{m}^{-1}$ de BAP (Liu et al., 1988), enquanto MarcianiBendezú et al. (1990) e Kiss et al. (1995) obtiveram as maiores taxas de multiplicação quando utilizaram respectivamente 4,5 e $5,0 \mathrm{mg} \mathrm{L}^{-1}$ do referido fitorregulador. Por outro lado, Calixto \& Siqueira (1996) verificaram que não houve diferença significativa entre os níveis de BAP, que variaram de 0 a 14 $\mathrm{mg} \mathrm{L}^{-1}$, na proliferação de brotos de abacaxizeiro. As discrepâncias entre os resultados obtidos pelos diversos autores e os obtidos neste trabalho devemse provavelmente às diferenças varietais, bem como aos diferentes protocolos utilizados.

Para massa fresca das plântulas, o uso de $1,5 \mathrm{mg} \mathrm{L}^{-1}$ de BAP na ausência de ágar foi superior aos demais (4,46 g), como mostra a Figura 3. Segundo Macedo et al. (2003), pequenas concentrações de BAP (1,0 $\left.\mathrm{mg} \mathrm{L}^{-1}\right)$, conjugadas com ANA (0,5 $\left.\mathrm{mg} \mathrm{L}^{-1}\right)$, proporcionaram maior peso da massa fresca de plântulas de abacaxizeiro. Ainda, de acordo com esses autores, os meios semi-sólidos e líquidos não apresentaram vitrificação, podendo ser recomendados em virtude da redução de custo e maior agilidade na preparação dos mesmos. Não houve diferença significativa pelo teste de regressão entre as concentrações 5,0 e 7,5 g L ${ }^{-1}$ de agar.

Para a variável massa seca das plântulas, que apresenta o crescimento real dos explantes, apenas as concentrações de ágar mostraram resultados significativos, obtendo-se melhores respostas na ausência deste componente. O

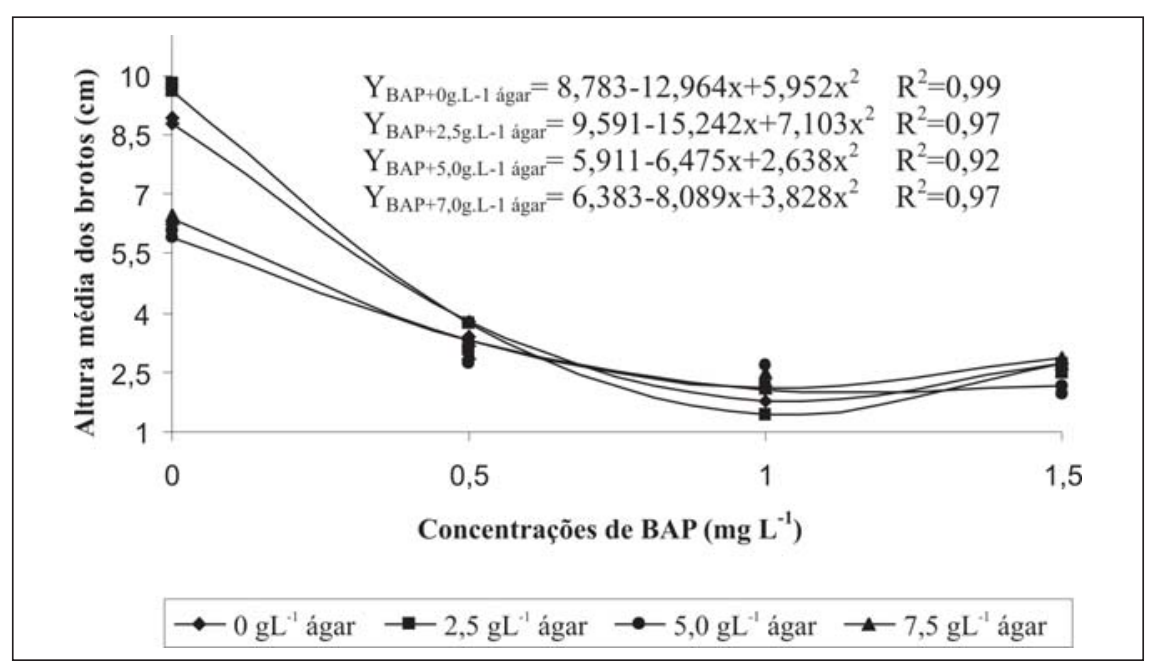

Figura 1. Altura média de brotos de abacaxizeiro ornamental em diferentes concentrações de BAP e ágar, 45 dias após a inoculação dos explantes (Sprout average high of ornamental pineapple plantlets, 45 days after inoculation with various BAP and agar concentrations). Lavras, UFLA, 2006.

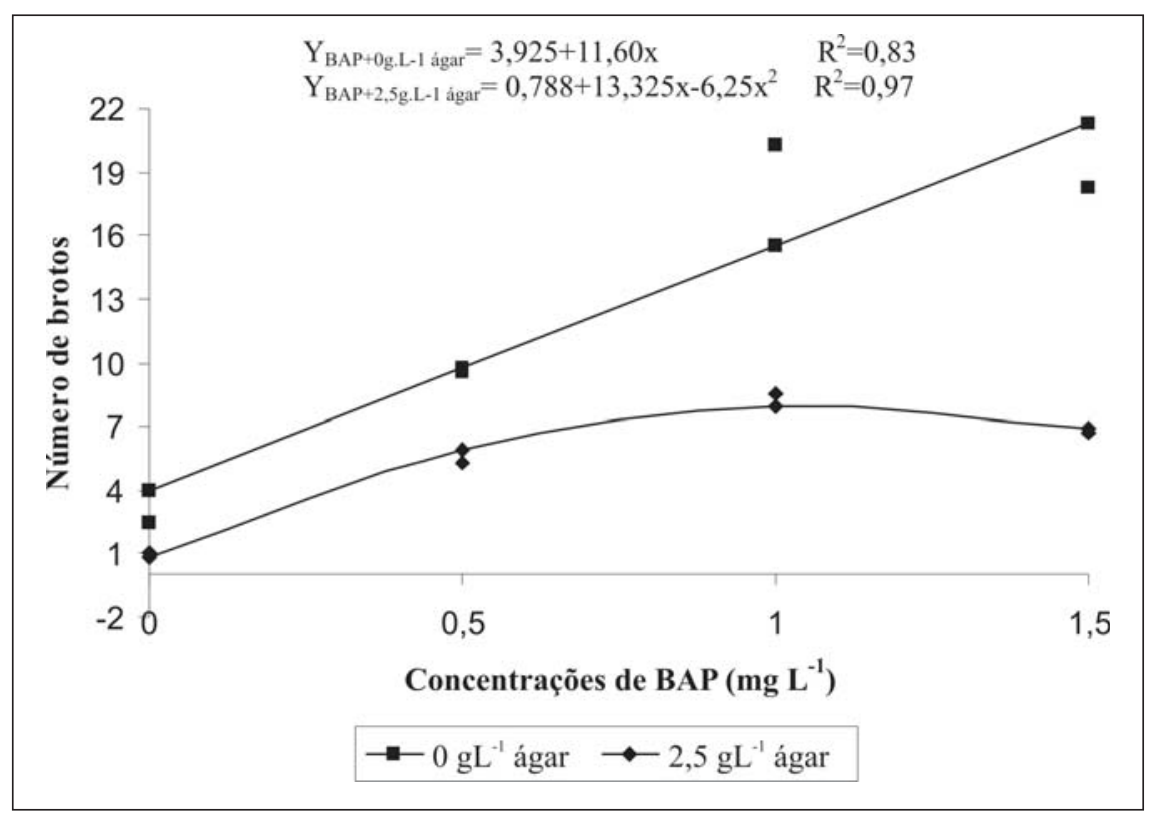

Figura 2. Número médio de brotos de abacaxizeiro em diferentes concentrações de BAP e ágar, 45 dias após a inoculação dos explantes (Average sprouts number of ornamental pineapple plantlets, 45 days after inoculation with various BAP and agar concentrations). Lavras, UFLA, 2006.

aumento das dosagens de ágar proporcionou queda linear desta variável $\left(\mathrm{Y}=0,226-0,005 x \mathrm{R}^{2}=0,93\right)$. Segundo Caldas et al. (1998), os meios líquidos possuem a vantagem de preparo mais rápido e mais barato do que os sólidos, além de favorecem a absorção de nutrientes e minerais pelas plântulas, viabilizando o crescimento vegetativo.

Os melhores resultados para comprimento médio da parte aérea foram obtidos com o emprego de $0,48 \mathrm{mg} \mathrm{L}^{-1}$ de
ANA em combinação com 2,5 g L ${ }^{-1}$ de ágar, atingindo em média 9,11 cm. Contrariamente, Macedo et al. (2003), observaram maior alongamento da parte aérea do abacaxizeiro com o uso de concentrações menores de ANA. Os autores observaram maior altura utilizando 0,25 $\mathrm{mg} \mathrm{L}^{-1}$ de ANA combinado a 0,5 mg $\mathrm{L}^{-1}$ de BAP e $0,12 \mathrm{mg} \mathrm{L}^{-1}$ de ANA combinado a $0,25 \mathrm{mg} \mathrm{L}^{-1}$ de BAP. Utilizando 2,5 $\mathrm{g} \mathrm{L}^{-1}$ de ágar, o comprimento da parte aérea aumentou proporcional- 


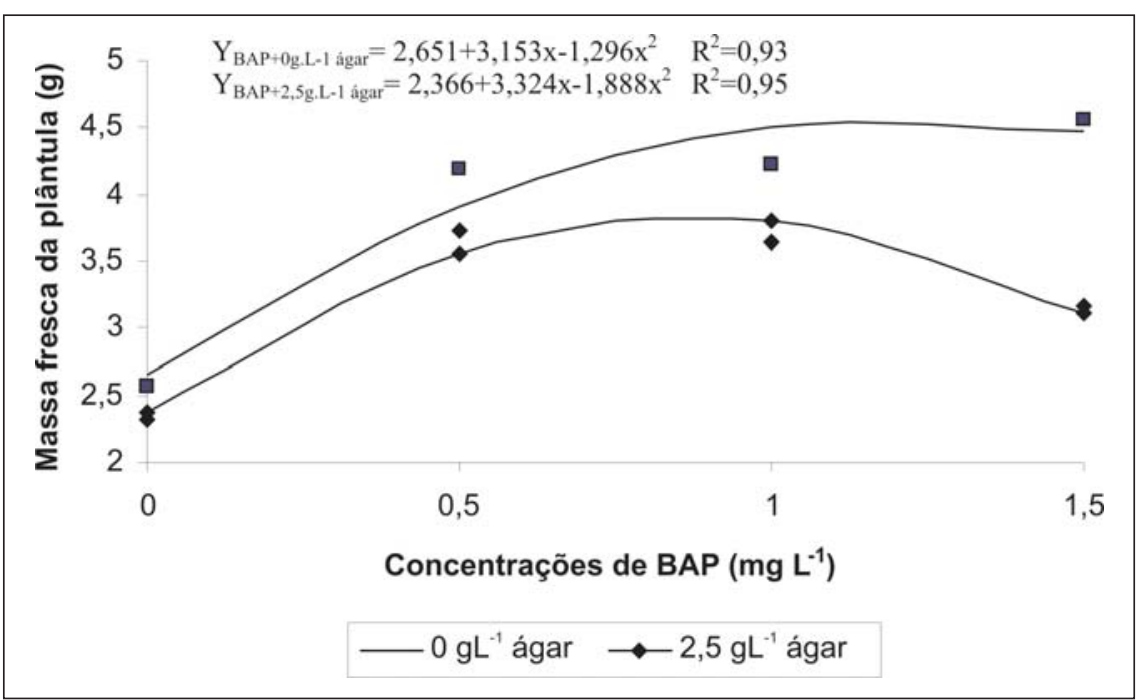

Figura 3. Massa fresca de plântulas de abacaxizeiro ornamental em diferentes concentrações de BAP e ágar, 45 dias após a inoculação dos explantes (Fresh mass of ornamental pineapple plantlets, 45 days after inoculation with various BAP and agar concentrations). Lavras, UFLA, 2006.

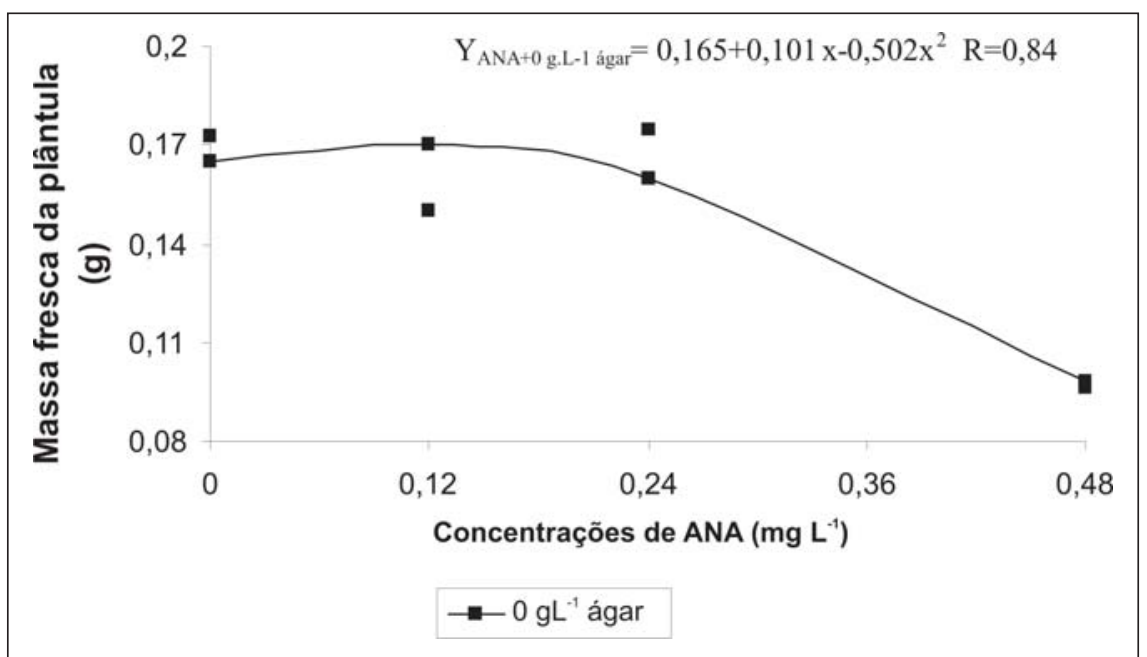

Figura 4. Massa fresca de plântulas de abacaxizeiro ornamental em diferentes concentrações de ANA e ágar, 45 dias após a inoculação dos explantes (Fresh mass of ornamental pineapple plantlets, 45 days after inoculation with various ANA and agar concentrations). Lavras, UFLA, 2006.

mente às concentrações de ANA testadas. Pierik et al. (1984), já haviam constatado a eficiência do ANA para promover o crescimento da parte aérea de bromeliáceas.

O número médio de raízes obtido com a concentração de $0,24 \mathrm{mg} \mathrm{L}^{-1}$ foi muito semelhante ao obtido com $0,48 \mathrm{mg}$ $\mathrm{L}^{-1}$ de ANA combinado com 2,5 $\mathrm{g} \mathrm{L}^{-1}$ de ágar. Macedo (2003) confirmou a inibição da formação de raízes nos explantes cultivados em meio de cultura na presença de BAP e que ao contrário, foi estimulada pela presença de ANA.
A variável comprimento médio do sistema radicular mostrou-se superior na ausência de ANA e ágar. A partir da concentração $0,24 \mathrm{mg} \mathrm{L}^{-1}$ de ANA o número médio de raízes estabilizou-se, porém com comprimentos menores quando comparados com aqueles resultados obtidos em meio sem regulador de crescimento e na ausência de agente solidificante. Grattapaglia \& Machado (1998) afirmam que o crescimento das raízes pode ser inibido pela presença de auxina. Provavelmente, o excesso de ANA endógeno não permitiu um alon- gamento satisfatório. Além disso, comparando-se o ocorrido com a parte aérea, a ausência de BAP também promoveu maior alongamento.

A atividade fisiológica das auxinas depende não apenas daquelas adicionadas ao meio, mas também do AIA no interior dos tecidos cultivados e da interação entre os dois (Pasqual et al., 2001). Fatores que afetam os níveis naturais de AIA e atividade deste composto podem, desse modo, ser importantes para controlar o crescimento e a morfogênese na cultura de tecidos de plantas usadas para micropropagação.

Apenas a ausência de ágar mostrou resultados significativos, proporcionando o maior peso de massa fresca e seca da parte aérea (2,60 e 0,17 g, respectivamente) na ausência de ANA (Figura 4). Este resultado pode ser compreendido, visto que as auxinas são promotoras da formação do sistema radicular.

Como já foi mencionado anteriormente, o uso de meios líquidos viabilizam a absorção de nutrientes e minerais presentes no meio de cultura, favorecendo o acúmulo de matéria fresca e seca no explante.

A multiplicação in vitro do abacaxi ornamental é viável em meio MS líquido acrescido de BAP $1,5 \mathrm{mg} \mathrm{L}^{-1}$ e o enraizamento também em meio MS líquido, na ausência de reguladores de crescimento.

\section{REFEFÊNCIAS}

ALMEIDA WAB; SANTANA GS; RODRIGUEZ APM; COSTA MAPC. 2002. Optimization of a protocol for the micropropagation of pineapple. Revista Brasileira de Fruticultura 24: 296-300.

BORGES NSS; CORREIA D; ROSSETTI AG. 2003. Influência do meio bifásico na multiplicação de gemas e no alongamento de brotos in vitro de Ananas comosus var. erectifolius Miller. Revista Brasileira de Horticultura Ornamental 9: 37-44.

CALDAS LS; HARIDASAN P; FERREIRA ME. 1998. Meios nutritivos. In: TORRES AC; CALDAS LS; BUSO JA. (eds). Cultura de tecidos e transformação genética de plantas. Brasília: Embrapa. p. 87-132.

CALIXTO MC; SIQUEIRA DL. 1996. Efeito do BAP e ferimentos na micropropagação do abacaxizeiro (Ananas comosus (L.) Merril) cV Smooth Cayenne. In: CONGRESSO BRASILEIRO DE FRUTICULTURA, 14. Anais... Londrina:IAPAR, 561p. 
CORREIA D; OLIVEIRA PMA; RIBEIRO KA; SILVEIRA MRS. 1999. Avaliação da multiplicação in vitro do abacaxi ornamental (Ananas lucidus Miller). Fortaleza: Embrapa Agroindústria Tropical. 2p. (Pesquisa em andamento, 56).

GALLO LA; CROCOMO OJ. 1995. A cultura de tecidos em fitopatologia. In: FILHO AB; KIMATI H; AMORIM L. (eds). Manual de fitopatologia: princípios e conceitos. São Paulo: Agronômica Ceres. p.495-505.

GEORGE EF. 1993. The components of culture media. In: GEORGE EF; SHERRINGTON PD. (eds). Plant propagation by tissue culture. Great Britain: Exegetice Limited. p. 273-343.

GEORGE EF. 1996. Plant propagation by tissue culture, part 1 - the technology. Ed. Edington: Exegetics Limited. 1574 p.

GRATTAPAGLIA D; MACHADO MA. 1998. Micropropagação. In: TORRES AC; CALDAS LS; BUSO JA. (eds). Cultura de tecidos e transformação genética de plantas. Brasília: Embrapa p. 183-260.

HU CY; WANG PJ. 1983. Meristem, shoot tip and bud cultures. In: EVANS DA; SHARP WR; AMMIRATO PV; YAMADA Y. (eds). Handbook of plant cell culture - techniques for propagation and breeding. New York: MacMillan Publishing Company. p. 177-277.

KISS E; KISS J; GYULAI G; HESZKY LE. 1995. A novel method for rapid micropropagation of pineapple. HortScience 30: 127-129.

KRIKORIAN AD. 1991. Medios de cultivo: generalidades, composición y preparación. In: ROCA WH; MROGINSKI LA. (eds.). Cultivo de tejidos em la agricultura - Fundamentos y aplicaciones. Cali: CIAT. p. 41-78.

LEAL F; AMAYA L. 1991.The Curagua (Ananas comosus var. erectifolius, Bromeliaceae) Crop in Venezuela. Economic Botany 45: 216-224.
LIU LJ; ROSA-MARQUES E; LIZARDE E. 1988.In vitro propagation of spineless Red Spanish pineaple. Phytopathology 77: 17111716.

MACEDO CEC; SILVA MG; NOBREGA FS; MARTINS PM; BARROSO PAV; ALLOUFA MAI. 2003. Concentrações de ANA e BAP na micropropagação de abacaxizeiro L. Merrill (Ananas comosus) e no cultivo hidropônico das plântulas obtidas in vitro. Revista Brasileira de Fruticultura 25: 501-504.

MARCIANI-BENDEZÚ J; PINTO JEBP; PASQUAL M. 1990. Efeito de 6benzilaminopurina (BAP) sobre a proliferação de brotos de abacaxizeiro, a partir de plântulas produzidas in vitro. Revista Brasileira de Fruticultura 12: 35-39.

MONETTE PL. 1986. Micropropagation of kiwifruit using non-axenic shoot tips. Plant Cell, Tissue and Organ Culture 6: 73-82.

MOREIRA MA. 2001. Produção e aclimatização de mudas micropropagadas de abacaxizeiro Ananas comosus (L) Merril cv. Pérola. Lavras: UFLA. 81p. (Tese doutorado).

MURASHIGE T. 1974. Plant growth substances in commercial uses of tissue culture. In: SKOOG F. (ed). Plant Growth Substances p. 426-434.

OLIVEIRA PD. 1994. Propagação in vitro de crisântemo (Dendranthema grandiflora Tzelev.) cv. Orange Reagen. Lavras: UFLA. 116 p. (Tese mestrado).

PAIVA PDO. 1997. Propagação in vitro de gloxínia. Revista brasileira de Horticultura Ornamental 3: 29-41.

PASQUAL M; HOFFMANN A; RAMOS JD. 2001. Cultura de tecidos - tecnologia e aplicações. Introdução: Situação $e$ Perspectivas. Lavras: UFLA/FAEPE. 72 p.
PASQUAL M; SILVA AB; MACIEL ALR; PEREIRAAB; ALVES JMC. 1998. Efeito da cianimida hidrogenada e benzilamino purina na proliferação in vitro de brotos de morangueiro (Fragaria x ananassa Duch.) cv. Princesa Isabel. Revista da Universidade de Alfenas 4: 115-119.

PEIXOTO PHP; PASQUAL M. 1995. Micropropagação da videira: efeitos do $\mathrm{pH}$ e do ágar. Revista Ceres 42: 431-443.

PIERIK RLM; STEEGMANS HHM; HENDRIKS J. 1984. The influence of naphthaleneacetic acid on the growth of in vitro cultivated seedling of Bromeliaceae. Scientia Horticulturae 24: 193-199.

ROCCA WM; MROGINKI LA. 1991. Cultivo de tejidos in la agricultura: fundamentos $y$ aplicaciones. Colômbia: Centro Internacional de Agricultura Tropical. 66 p.

SINGHA S. 1982. Influence of agar concentration on in vitro shoot proliferation of Malus sp. 'Almey' and Pyrus communs 'Seckel'. Journal of the American Society for Horticultural Science 107: 657-660.

SINGHA S. 1984. Influence of two comercial agar on in vitro proliferation of 'Almey' crabapple and 'Seckel' pear. HortScience 19: 227-228.

SMITH LB; DOWS RJ. 1979. Bromelioideae (Bromeliaceae) Flora Neotropica Monograph. p. 1493-2142.

ZAER JB; MAPES MO. 1985. Action of growth regulators. In: BONGA JM; DURZAN DJ. (eds). Tissue culture in florestry. Martinus Nijhoff Publishers. p. 231-255. 